\title{
Using sustainability criteria in law
}

\section{Evgenia Pavlovskaia}

Law Faculty, Lund University, Sweden

\section{Email address:}

evgenia.pavlovskaia@jur.lu.se

\section{To cite this article:}

Evgenia Pavlovskaia. Using Sustainability Criteria in Law. International Journal of Environmental Protection and Policy. Vol. 1, No. 4, 2013, pp. 76-78. doi: 10.11648/j.ijepp.20130104.15

\begin{abstract}
The purpose of the article is to raise interest for using sustainability criteria as a means to promote and safeguard sustainability for traded products and their production. The focus is put on how sustainability criteria can be efficiently used in legal constructions. Practical examples from the biofuel sector are provided.
\end{abstract}

Keywords: Sustainability Criteria, Biofuels, Environmental Law

\section{Introduction}

How can we efficiently promote and safeguard sustainability for traded products and their production? [1] Different means or their combinations can be used for this purpose, such as eco-labels [2], environmentally friendly standards [3], sustainability criteria, spreading relevant information to involved actors and originating further scientific investigations.

\section{Why Should Sustainability Criteria be Chosen?}

Simply put, sustainability criteria are "requirements on sustainability that have to be fulfilled for the certification of a product or production process" [4]. Using them is an emerging international practice, which purpose is to promote and safeguard the desired quality of products and their production methods. Sustainability criteria can be of technical, economic, social and environmental character. So far sustainability criteria have been dominantly used in voluntary sustainability standards that have been initiated by private, non-governmental actors at different levels; coffee, cotton and forest industries are prominent examples here. The development of binding EU regulations for transport biofuels, with reference to mandatory sustainability criteria for this type of a product [5], has urged discussions of using sustainability criteria in a legal context.

Sustainability criteria have potential to improve and protect the quality of locally produced and imported products. Applying sustainability criteria in a legal framework, as well as suitable mechanisms for their practical implementation have not been thoroughly researched. From the environmental perspective, which is very urgent today, establishment of sustainability criteria should be viewed in relation to resources and possibilities that the planet can supply us with [6]. As an example of the minimum delimitations, the development of products and their production methods should not result in destruction of the existing eco-systems, harm biodiversity or pollute the environment.

The central question that is stated in this article is how and with the help of what means sustainability criteria should be used and incorporated in legal frameworks. The main focus lies on the aspects that are relevant and important for sustainability criteria to function appropriately in a legal context. These aspects have been chosen on the basis of the existing scientific literature and tested on empirical material. Without taking these aspects into account, it is difficult for a legal framework with sustainability criteria to be efficient and achieve its aims.

\section{How Should Sustainability Criteria be used in Law?}

There are certain aspects that, according to my research, answer for how sustainability criteria should be incorporated and used in a legal context. Totally five main aspects have been distinguished.

The first aspect deals with the interpretation of the concept "sustainability" in the branch sustainability criteria are created for. The questions that should be answered here are "What to sustain?" and "How to sustain this with the help of sustainability criteria?". The first question specifies the scope and direction of sustainable protection or sustainabil- 
ity quality that the planned sustainability criteria are aimed to uphold. It provides grounds for the future assessment of how the sustainability criteria will be fulfilled. In legal terms, the answer to the first question can be regarded as the formulation of the environmental goal, which a legal framework with sustainability criteria has.

The other question "How to sustain this with the help of sustainability criteria?" requires thorough analysis of what types and groups of sustainability criteria should be used, in order to achieve the desirable sustainable protection and sustainability quality. This might be within the competence of technical experts to work out a list of sustainability criteria necessary for a certain production branch or product. The task of law-makers should be to formulate the suggested sustainability criteria in a precise and transparent way, so that they can be implemented without difficulties.

Lists of sustainability criteria for a particular product can be very extensive. As an example, sustainability criteria for biofuels can be as many as 127 [7], and this figure is not final. It is doubtful whether such long lists can successfully be incorporated in a legal framework, especially if different types of the same product are in demand of different sustainability criteria. Various methods for dealing with this challenge have been suggested (and this can be regarded the second aspect of including sustainability criteria in a legal context). One of the solutions is to divide a long list into a smaller number of main categories or issues. They can be included in a legal text with an explanation that an acceptable environmental quality within each category should be acquired. Later on, more detailed and specified sustainability criteria within each category can be worked out and attached to the main body of a legal framework.

The third aspect is that sustainability criteria should be accompanied by indicators or other instruments that would measure and help to assess the fulfilment of the sustainability criteria. These indicators and instruments can be worked out on the basis of technical information, which is special for different products. For example, a sustainability criterion for biofuels that says that this type of a product shall achieve a minimum level of greenhouse gas savings, should also contain a reference to how greenhouse gas savings are calculated, and what main stages in production process should be taken into account.

The fourth aspect is that sustainability criteria should not be incorporated in a legal framework as a single unit. They should be accompanied by other elements necessary for their practical implementation, such as enforcement of sustainability criteria and control of their fulfillment. In the case of biofuels, it can be rules that contain instructions to authorities, biofuel producers and biofuel distributors about what they should and should not do, for sustainability criteria for this product to be fulfilled. Supplementary elements are almost obligatory for a legal framework to function.

The final aspect of including sustainability criteria in a legal framework is that compatibility of the proposed sus- tainability criteria with the already existing laws and regulations at the international, regional and national levels should be checked. It is easy to write about this aspect, but in practice this compatibility is not easy to be achieved. Contradictions with the already existing regulations can be difficult to resolve, especially if we talk about the rules of the World Trade Organization (WTO), which dominate in the international trading system. Compatibility with other biand multilateral regulations is also important.

The suggested list of the aspects relevant for the use of sustainability criteria in legal frameworks can evidently be modified and expanded. It can also be treated as a ground for more elaborated theoretical discussions about the notion of sustainability criteria from the judicial perspective. Among the issues that require further investigation is how sustainability criteria should be included in a legal framework together with other elements that ensure their practical implementation.

\section{Why Including Sustainability Criteria in a Legal Context?}

After going through the presented material, a question can arise, why it is needed to use sustainability criteria in legal frameworks. Indeed, there are a lot of voluntary sustainability standards with sustainability criteria that would fulfill approximately the same function. The answer to this question can be that a binding legal context creates more order in the branch, where sustainability criteria are used; it has the potential to establish a more profound and scientifically grounded environmental protection; it offers more effective control and assessment measures; it provides more secure opportunities for long future planning; as well as it promotes and safeguards investments. On the other hand, sustainability criteria in legal frameworks are less flexible to technological and market changes, and it can be a costly alternative. All these arguments should be considered, when the most appropriate form of using sustainability criteria is being chosen.

\section{Acknowledgments}

I would like to thank the Law Faculty at Lund University, Sweden, and Vilhelm Persson, its Head, for providing extremely convenient research conditions. I would like to express my deep gratitude to Annika Nilsson, Karin Ericsson and Bengt Lundell, my research supervisors, and Carl Dalhammar, my critical opponent, for their guidance and useful critiques of the present research work. My special thanks are extended to the Johan and Jakob Söderberg Funding in Stockholm for its financial support. Finally, I wish to thank the Science Publishing Group for the supportive review of the manuscript of this article. 


\section{References}

[1] The increase in consumers' environmental awareness and their concerns about the environmental impact of the products they purchase have resulted in many companies realizing the potential of sustainable product development [Du Toit, B.- J. (2011), The effects of eco-labelling on consumer behaviour in the non-foods fast-moving consumer goods category: A study of South African consumers, p. 1, a thesis, Stellenbosch University.

[2] The aim of eco-labels can be described as to differentiate products on the basis of their environmental and social impacts, which enables consumers to make informed purchasing decisions. Eco-labels are intended to incentivize better practices by industry [Kirby, D., S., Visser, C., Hanich, Q., Assessment of eco-labelling schemes for Pacific tuna fisheries (2013), p. 1, in Marine Policy, accepted 13 May 2013, pp. $1-11]$.

[3] According to the definition suggested by Lewandowski, I. and Faaij, A. (2006), environmentally friendly standards, or sustainability standards, can be described as sets of criteria and indicators that describe the requirements a sustainable product or process has to fulfil [Lewandowski, I., Faaij, A. (2006), Steps towards the development of a certification system for sustainable bio-energy trade, p. 90, in Biomass and Bioenergy, 30 (2006), pp. 83-104].

[4] In comparison to traditional technical criteria that can be used to identify and specify the quality of a product, basing on the set of its physical parameters, sustainability standards provide detailed specifications, setting environmental and social characteristics for the production process itself, with clear reference to the main pillars of sustainable development [Daviron, B., Vagneron, I., From Commoditisation to De-commoditisation and Back Again: Discussing the Role of Sustainability Standards for Agricultural Products (2011), p. 91, in Development Policy Review, January 2011, vol. 29, issue 1, pp. 91-113].
[5] Directive 2009/28/EC on the promotion of the use of energy from renewable sources and amending and subsequently repealing Directives 2001/77/EC and Directive 2009/30/EC (on the quality of transport fuels) amending Directive $98 / 70 / \mathrm{EC}$ as regards the specification of petrol, diesel and gas-oil and introducing a mechanism to monitor and reduce greenhouse gas emissions and amending Council Directive $1999 / 32 / E C$ as regards the specification of fuel used by inland waterway vessels and repealing Directive 93/12/EEC.

[6] This has been also called the carrying capacity of the biosphere, which must not be exceeded [Wackernagel, M., Schulz, N., B., Deumling, D., Linares, A., C., Jenkins, M., Kapos, V., Monfreda, C., Loh, J., Myers, N., Norgaard, R., Randers, J., Tracking the ecological overshoot of the human economy (2002), p. 9266, in Proceedings of the National Academy of Sciences of the United States of America, July 2002 vol. 99, no. 14, pp. 9266-9271; Haberl, H., Fischer-Kowalski, M., Krausmann, F., Weisz, H., Winiwarter, V., Progress towards sustainability? What the conceptual framework of material and energy flow accounting (MEFA) can offer (2004), p. 200, in Land Use Policy 2004, vol. 21, issue 3, pp. 199-213; Kitzes, J., Wackernagel, M., Loh, J., Peller, A., Goldfinger, S., Cheng, D., Tea, K., Shrink and share: humanity's present and future Ecological Footprint (2008), p. 467, in Phil. Trans. R. Soc. B, February 2008 vol. 363 no. 1491, pp. $467-475$; Cairns, J., Threats to the Biosphere: Eight Interactive Global Crises (2010), p. 1911, in Journal of Cosmology, June 2010, vol. 8, pp. 1906 - 1915, Department of Biological Sciences, Virginia Polytechnic Institute].

[7] Lewandowski, I., \& Faaij, A. (2004). Steps towards the development of a certification system for sustainable biomass trade-analysis of existing approaches. Utrecht University. Utrecht, the Netherlands; Smeets, E. M. W., Faaij, A. P. C., \& Lewandowski, I. M. (2005). The impact sustainability criteria on the costs and potentials of bioenergy production. An exploration of the impact of the implementation of sustainability criteria on the costs and potential of bioenergy production applied for case studies in Brazil and Ukraine, p. 7. 